\title{
European network for Health Technology Assessment, EUnetHTA: Planning, development, and implementation of a sustainable European network for Health Technology Assessment
}

\section{Finn Børlum Kristensen}

National Board of Health, Copenhagen, Denmark and University of Southern Denmark

\section{Marjukka Mäkelä}

National Institute for Health and Welfare, Helsinki, Finland and University of Copenhagen

\section{Susanna Allgurin Neikter}

Swedish Council on Technology Assessment in Health Care

\section{Nina Rehnqvist}

Swedish Council on Technology Assessment in Health Care and Karolinska Institute

\section{Lise Lund Håheim}

Norwegian Knowledge Centre for the Health Services

\section{Berit Mørland}

Norwegian Knowledge Centre for the Health Services

\section{Ruairidh Milne}

University of Southampton

\section{Camilla Palmhøj Nielsen}

National Board of Health, Copenhagen, Denmark and University of Copenhagen

\section{Reinhard Busse}

Technische Universität Berlin

\footnotetext{
We thank all thirty-four Associated Partners and thirty Collaborating Partners that were involved in EUnetHTA (see Supplementary Tables 1-3, which are available at www.journals.cambridge.org/thc2009004, where all partners are listed and where all other acknowledgements can be found together with acknowledgements for all EUnetHTA articles in this series). The EUnetHTA project was supported by a grant from the European Commission, Agreement number 2005110 (790621). The sole responsibility for the content of this article lies with the authors, and the European Commission is not responsible for any use that may be made of the information contained therein. The EUnetHTA Project was led by the Danish Agency for HTA, DACEHTA, in the National Board of Health together with the Executive Committee of Work Package Lead Partner organizations represented in the authorship of this article and with the Steering Committee of all Associate Partners.
} 
Børlum Kristensen et al.

\title{
Sun Hae Lee-Robin
}

French National Authority for Health

\section{Claudia Wild}

Ludwig Boltzmann Institute of Health Technology Assessment

\section{Mireia Espallargues}

Catalan Agency for Health Technology Assessment and Research

\author{
Julia Chamova \\ National Board of Health, Copenhagen, Denmark

\section{for the European network for Health Technology Assessment (EUnetHTA)}

\begin{abstract}
Objectives: The European network on Health Technology Assessment (EUnetHTA) aimed to produce tangible and practical results to be used in the various phases of health technology assessment and to establish a framework and processes to support this. This article presents the background, objectives, and organization of EUnetHTA, which involved a total of sixty-four partner organizations.

Methods: Establishing an effective and sustainable structure for a transnational network involved many managerial, policy, and methodological tools, according to the objective of each task or Work Package. Transparency in organization, financial transactions, and decision making was a key principle in the management of the Project as was the commitment to appropriately involve stakeholders.

Results: EUnetHTA activities resulted in a clear management and governance structure, efficient partnership, and transnational cooperation. The Project developed a model for sustainable continuation of the EUnetHTA Collaboration.

Conclusions: The EUnetHTA Project achieved its goals by producing a suite of practical tools, a strong network, and plans for continuing the work in a sustainable EUnetHTA Collaboration that facilitates and promotes the use of HTA at national and regional levels. Responsiveness to political developments in Europe should be balanced with maintaining a high level of ambition to promote independent, evidence-based information and well-tested tools for best practice based on a strong network of HTA institutions.
\end{abstract}

Keywords: Health, Technology assessment, biomedical, Biomedical technology, Evidence-based health care, Information management, Evaluation studies as topic, Delivery of health care, Public policy, Internationality, European Union

Most countries experience an increasing need to prioritize services and ensure quality and safety in health care. They also recognize a need for reliable and broadly accepted documentation on healthcare interventions, that is, "health technologies" for professionals, institutions, and decision makers. Moreover, patients, health professionals, researchers, and industries move across borders, demanding transparency on availability, effectiveness, appropriateness, and cost-effectiveness of interventions. The challenge is how best to use resources more efficiently and to free resources to meet unmet health needs with effective interventions, given economic constraints. Technologies having the highest proven effectiveness should be promoted while taking organizational, economic, societal, and ethical aspects into consideration (21). Many European countries use HTA to assist in making decisions and policies in the health field, and public health and medical decision makers in Europe are now formally building HTA into certain policy, governance, reimbursement, or regulatory processes (27). This has raised the issue of intensifying HTA collaboration in the European Union (EU). HTA is, by definition, context specific, and a system to facilitate transnational collaboration in HTA should acknowledge this.

\section{HEALTH TECHNOLOGY ASSESSMENT}

Health technology assessment offers an approach for improving the knowledge base for healthcare policy and decision making across a broad range of technologies (22).

European network for Health Technology Assessment (EUnetHTA) developed an explanatory definition of health technology and health technology assessment extending from the INAHTA definition (17). Health technology is the application of scientific knowledge in health care and disease 
Box 1. European Projects to Promote Collaboration between Member States on HTA

- EUR-ASESS Project (1994-97) contributed to the establishment of a common and consistent understanding of HTA and also identified the need for information sharing among European countries (3)

- $\quad$ HTA Europe Project (1997-98) gave an overview of HTA in European Countries (4)

- ECHTA/ECAHI Project (2000-02) included a detailed analysis of how an approach to a permanent coordinating structure for HTA could be developed in Europe (20)

prevention. Health technology assessment (HTA) is a multidisciplinary process that summarizes information about the medical, social, economic, and ethical issues related to the use of health technology in a systematic, transparent, unbiased, robust manner. Its aim is to inform the formulation of safe, effective, health policies that are patient focused and seek to achieve best value. Despite its policy goals, HTA must always be firmly rooted in research and the scientific method. Examples of Health Technology are diagnostic and treatment methods, medical equipment, pharmaceuticals, rehabilitation and prevention methods, organizational and supportive systems within which health care is provided.

\section{HEALTH TECHNOLOGY ASSESSMENT IN EUROPE}

In Europe, HTA started on small scale in the 1970s. It grew throughout the 1980s and continues to do so (2). The European Commission has supported and funded several projects to promote collaboration of Member States on HTA $(3 ; 4 ; 20)$ (Box 1). However, there was no direct continuation of funding, and the network was discontinued after the latest project had been completed.

\section{International Collaboration among HTA Institutions}

Browsing the HTA Database substantiates that de facto duplication of efforts in HTA has increased during the past decade as the number and production volume of HTA entities has grown in Europe (18). Likewise, HTA organizations were confronted with methodological challenges and requirements to produce an increasing volume of high-quality reports within short timelines (26). Nordic HTA agencies conducted some joint projects, for example, on sleep apnea (24). These projects also included surveys of clinical practice. Remarkable practice variations and the need to put evidence into national contexts were demonstrated. Some INAHTA member agencies collaborated on assessments, for example, of bone density measurement and PET scanning (19). The need to develop practical international collaboration in HTA was realized by many HTA organizations, and political developments in the health arena in Europe provided the opportunity for such collaboration.

\section{European Developments at the Policy Level}

After the end of the ECHTA/ECAHI Project at least two European policy processes brought forward the political basis for European HTA. In May 2002, the High Level Group on Innovation and Provision of Medicines in the EU (G10) recommended that the European Commission organize a European process to reflect on how Member States could improve ways of sharing information and data requirements. The purpose would be to achieve greater certainty and reliability for all involved, even if their policy decisions might differ. One objective was to foster the development of HTA, including clinical and cost-effectiveness, in the Member States and the EU. This would aim to improve the value of HTA by sharing national experiences and data while recognizing that relative evaluation should remain a responsibility of Member States (12).

Conclusions of the Health Council (Health Ministers from EU Member States) in June 2002 on the issue of crossborder collaboration in health care were followed by a highlevel process to reflect on patient mobility and healthcare developments. A report was presented in 2003 (14). This document stated that HTA could assist policy makers in making informed decisions by providing evidence on medical, social, economic, and ethical issues concerning healthcare policy and practice. The report recommended inviting the European Commission to consider how a sustainable network and coordination function for health technology assessment could be organized and funded and to make an appropriate proposal.

In 2004, the European Commission established a High Level Group on Health Services and Medical Care (HLG) consisting of high-level officials from Member State ministries of health to endorse and implement the recommendations issued from the patient mobility reflection process. The HLG established several working groups, one of them on HTA. The group, chaired by Finland and involving sixteen Member States, was able to finish its report after a few months. This report stated that a network should address methods to develop common core information packages, support transferability of assessments, help Member States identify and prioritize topics, commission reports tailoring common core information to national health policy processes, and share methodologies, expertise, and practice issues.

The HLG work during 2004 resulted in a report that identified an urgent need to establish a sustainable network for HTA and proposed several steps starting with a 3-year project supported by the EU Public Health Program (15). This was endorsed by the Council of Ministers, and followed by a call for proposals in SANCO's work program for 2005 aiming at projects to establish a European network for HTA.

\section{Scope of This Article}

This article reports how fifty-nine organizations prepared and how sixty-four organizations implemented a project with an 
objective to establish a sustainable network for HTA in Europe (Supplementary Tables 1 and 2, which are available at www.journals.cambridge.org/thc2009004). We focus on the structures, methods, and tools for effective collaboration on HTA in Europe. Methods and tools for information sharing and communication, stakeholder involvement, and an internal evaluation are described and discussed in a series of articles coordinated for publication in this issue of the Journal $(1 ; 23 ; 25)$.

\section{Practical Methods and Tools for HTA}

A separate article provides an overview of the EUnetHTA Project's planning, development, and piloting of a suite of practical methodologies and tools for several key components of contemporary HTA, for example, assessment of new and existing technologies, adapting HTA information to new settings, informing policy on emerging technologies, monitoring the introduction of new technologies, and developing HTA capacity (22).

\section{OBJECTIVES}

The EUnetHTA Project was established to create an effective and sustainable network for HTA across Europe that could develop and implement practical tools to provide reliable, timely, transparent, and transferable information to contribute to HTAs in Members States.

The strategic objectives of the EUnetHTA Project were to reduce duplication of effort to promote more effective use of resources, increase HTA input to decision making in Member States and the EU to increase the impact of HTA, strengthen the link between HTA and healthcare policy making in the EU and its Member States, and support countries with limited experience in HTA.

EUnetHTA was a practical project and, hence, the specific objectives were of a practical nature. Table 1 describes the division of labor between Work Packages (WPs).

\section{METHODS}

The preparations and implementation processes to meet objectives and provide concrete results started in January 2005 when the Danish Centre for HTA (DACEHTA) in the National Board of Health wrote to the members of ECHTA/ ECAHI, the previous EU-supported project. DACEHTA suggested a "proposal network" and that a task force with Europe-wide representation construct a proposal for the European Commission. The task force included representatives from Denmark, Finland, France, Germany, Norway, Spain, Sweden, and the United Kingdom. It convened in February 2005 to share the work on producing a proposal within 2 months.

The resulting application for cofunding from the EU Public Health Program on behalf of thirty-five cofunding or- ganizations and twenty-four other organizations participating in the proposal was successful (Supplementary Tables 1 and 2).

\section{Establishing a Basic Structure for the EUnetHTA Project}

The EU grant was linked to a contract that included detailed financial sections and a section describing the project work, including a listing of milestones and deliverables (tangible scientific and other products) along the project's 3-year time line. This section was identical to the project description in the proposal, with some modifications by the secretariat and the task force in light of a reduced budget.

The EUnetHTA Project continued from 2006 to 2008 and comprised eight WPs. At the outset, thirty-four Associated Partners and one Main Partner participated in one or more WPs, contributed to the budget and received shares of the grant. One Associated Partner left in early 2006 due to internal restructuring and major changes in its profile. Originally, the project included twenty-four Collaborating Partners. This number grew to thirty Collaborating Partners by 2008 (Supplementary Table 1). Collaborating Partners contributed in kind (with their own resources) and did not contribute or receive resources from the budget. Several hundred individuals from Partner organizations were involved, and many senior staff members contributed to the work.

\section{Governance and Management Structure}

A Coordinating Secretariat headed by the project leader from the Main Partner, and assisted by a project coordinator, was in place to manage the project from day 1, and the Network's governance and management structure was developed and implemented during the first half year. Each WP was headed by a Lead Partner, in two cases involving a WP Co-Lead Partner. A Standard Operating Procedure (SOP) document was developed (Supplementary List 1, which is available at www.journals.cambridge.org/thc2009004).

All WPs had two or more face-to-face meetings distributed across Europe, one of them at an early stage in the work.

\section{Work Plans and Annual Reporting by All Work Packages}

The Secretariat and the WP Lead Partners developed a 3-year Work Plan. The Work Plan was reviewed and adjusted yearly to reflect changing needs and schedules. The Secretariat coordinated the development of the annual project reports with contributions from each WP and Associated Partner. Annual technical and financial reporting was required by the grant contract and served as an important tool for the Executive Committee (described below) and partners to monitor the Project's progress. 
Table 1. Overview: Objectives, Deliverables, Work Packages, and Work Package Lead Partners

Specific objectives
To establish the organizational and
structural framework for the network
with a supporting secretariat
To effectively disseminate and handle
HTA results, information sharing and
coordination of HTA activities through
the development and implementation of
elaborate communication strategies and
description of Clearinghouse
functionality

A requirement from EU to include internal evaluation throughout the project

To produce generic Core Models for HTAs on two essential categories of health technology questions: interventions and treatment, as well as Core HTAs on selected topics for each category

To develop and implement generic tools for adapting assessments made for one country to new contexts

To develop and implement effective tools to transfer HTA results into applicable health policy advice in the Member States and EU-including systems for identification and prioritization of topics for HTAs and assessment of impact of HTA advice

To structure prioritization for HTA and provide healthcare decision makers with policy relevant information on new and emerging technologies

To develop effective monitoring of emerging health technologies to identify those that will have the greatest impact on health systems and patients

To establish a support system for countries without institutionalized HTA activity
Deliverables

The EUnetHTA organizational structure including a supporting Secretariat

Final report from the project

EUnetHTA conference presenting the project results

Web site/Information platform

Communication strategy

A clearinghouse functionality - detailed identification of the clearinghouse needs of different target groups and consecutive structure development to be ready for practical application after 3 years

EUnetHTA conference presenting the project results

Internal evaluation of the project

Framework for external evaluation

Core HTA structure/mode

2 pilot examples of Core HTAs for different types of questions (e.g., diagnosis and treatment)

A handbook on Core HTA.

A Web-based toolkit for adapting Core HTA results from existing HTAs into other contexts including a HTA Glossary of adaptation

Applicability testing of core information from 2 existing HTA reports in various national environments using the toolkit

EUnetHTA Open Forum for stakeholders to exchange views and expectations/feedback on HTA

A book containing a systematic overview of the HTA \& healthcare policy links in selected Member States \& EU representing different health systems, remuneration systems, etc

A prototype of a structured information service on high volume, costly, rapidly developing, emerging technologies

A set of monitoring tools for emerging/new technologies

Handbook on HTA organizations. The handbook will compile the results and information extracted from the review and the survey of HTA organizations
No Work Packages and Lead Partners

1 Coordination

Main Partner DACEHTA—Danish Centre for HTA / National Board of Health (Denmark)

2 Communications

Lead Partner SBU-Swedish Council on Technology Assessment in Health Care (Sweden):

Co-Lead Partner DAHTA@DIMDI-German Agency for HTA at the German Institute for Medical Documentation and Information (Germany)

3 Evaluation Lead Partner NOKC - Norwegian Knowledge Centre for the Health Services (Norway)

4 Common core HTA

FinOHTA-Finnish Office for HTA (STAKES) (Finland)

5 Adapting existing HTAs from one country into other settings Lead Partner NCCHTA-National Coordinating Centre for HTA (United Kingdom)

6 Transferability of HTA to health policy Lead Partner DACEHTA-Danish Centre for HTA / National Board of Health (Denmark)

7 Monitoring development for emerging new technologies and prioritization of HTA

Lead Partner HAS—Haute Autorité de santé / French National Authority for Health (France)

7 Monitoring development for emerging new technologies and prioritization of HTA

Co-Lead Partner LBI@HTA_Ludwig Boltzman Institute of Health Technology Assessment (Austria)

8 System to support HTA in Member States with limited institutionalization of HTA

Lead Partner CAHTA - Catalan Agency for Health Technology Assessment and Research (Spain)

HTA, health technology assessment; EUnetHTA, European network for Health Technology Assessment. 


\section{Information, Communication, and Clearinghouse}

From the outset the Project used contemporary communication and information technology and considered an integrated information system. Work Package 2 (WP2) developed a communication strategy where the main tool was a EUnetHTA Web site (www.eunethta.net) developed and hosted by the WP2 Lead Partner, SBU, based on marketing theory with input from Partners and information from the Secretariat (1). A separate WP2 subgroup developed a document and test computer interface describing a clearinghouse prototype. An e-meeting facility, serviced by a commercial provider was used for on-line group work (http://www.saba.com/products/centra/). This facility was freely available to the Partners for their EUnetHTArelated work and other collaboration activities within their organizations. It enabled audio Internet contact between emeeting participants, sharing of software applications and documents on screen, audio discussion, text chat, voting, etc. E-meetings were recorded and placed on a server for download by participants. Individual and group e-mails were also used extensively. WP2 continued to develop the HTA Information System throughout the autumn of 2008 , focusing on prioritized needs of Partners.

\section{Stakeholder Involvement}

The EUnetHTA Project emphasized involvement of stakeholders in its processes. EUnetHTA set out to identify relevant groups, develop contact and consultation, collect feedback and advice, and discuss the future of EUnetHTA. A work stream in Work Package 6 (WP6) was dedicated to this purpose (25), and several WPs involved stakeholders in public consultation of draft products.

The first involvement of stakeholders was in a half-day Forum organized by EUnetHTA in the European Health Forum Gastein 2006 (13), where representatives from hospital management, industry, and healthcare management discussed European HTA with representatives from public health, government, the EU Commission, international funders, and HTA agencies.

\section{Planning Permanent EUnetHTA Collaboration}

As the Project reached its midpoint the Executive Committee developed the first draft of a proposal for a sustainable European HTA collaboration with a coordinating secretariat. Comments on the proposal were collected from the Associated Partners during early autumn 2007, and a revised proposal underwent public consultation during the final months of 2007. After a second round of review and public consultation and after reaching agreement on amendments in May 2008, the Steering Committee unanimously endorsed the proposal, which was then made public.

\section{EUnetHTA Participation in European Health Policy Processes}

The successful involvement of HTA experts in the HLG working group on HTA in 2004 was picked up by the EUnetHTA Project in several ways. During 2006, a public launch of the Project that included a publication in a European health policy journal, EuroHealth, and a Forum on HTA in Europe, held in Gastein, helped to make the Project known outside of the immediate HTA environs (13;21). Early in 2007, EUnetHTA contributed to the EU Commission consultation regarding community action on health services, which was a step in preparing an EU Directive on cross-border health care. Likewise, EUnetHTA commented on the document Health in Europe; A Strategic Approach during the development of the EU Health Strategy 2008-13. These contributions are available on the Web site (www.eunethta.net). Partners were encouraged to communicate their views on the value of EUnetHTA to their respective ministries.

EUnetHTA was invited to present its progress to the EU HLG during first and third year. After an invitation to a meeting in the Relative Effectiveness Working Group of the Pharmaceutical Forum, which was a result of the G10 reflection process (12), EUnetHTA provided information to the working group and contributed comments to drafts. A report was published in 2008 (16). A parallel session on resource allocation was dedicated to HTA in the program of the WHO European Ministerial Conference on Health Systems: Health Systems, Health, and Wealth in Tallinn in 2008 (29). A EUnetHTA satellite session was also included.

\section{Internal Evaluation}

The EU required a WP for evaluation as part of the contract, and the Project could decide on planning, implementation, and reporting. Under the leadership of NOKC, Work Package 3 (WP3) applied regular, formal assessment of EUnetHTA plans and reporting together with questionnaires and interviews and provided evaluation feedback to the Executive Committee during the Project (23).

\section{RESULTS}

The governance, management structures, and organizational tools for effective collaboration on HTA in Europe proved able to effectively support the scientific work to meet the defined objectives. An overview of results of the practical methodologies and tools for HTA developed in EUnetHTA appears in another article in this issue (22).

\section{Governance and Management}

An early result was a stable structure with a Steering Committee (the "general assembly" having the ultimate decision power in the Project) consisting of all Associated Partners and an Executive Committee of WP Lead Partners. The Steering Committee coordinated and led EUnetHTA and was 


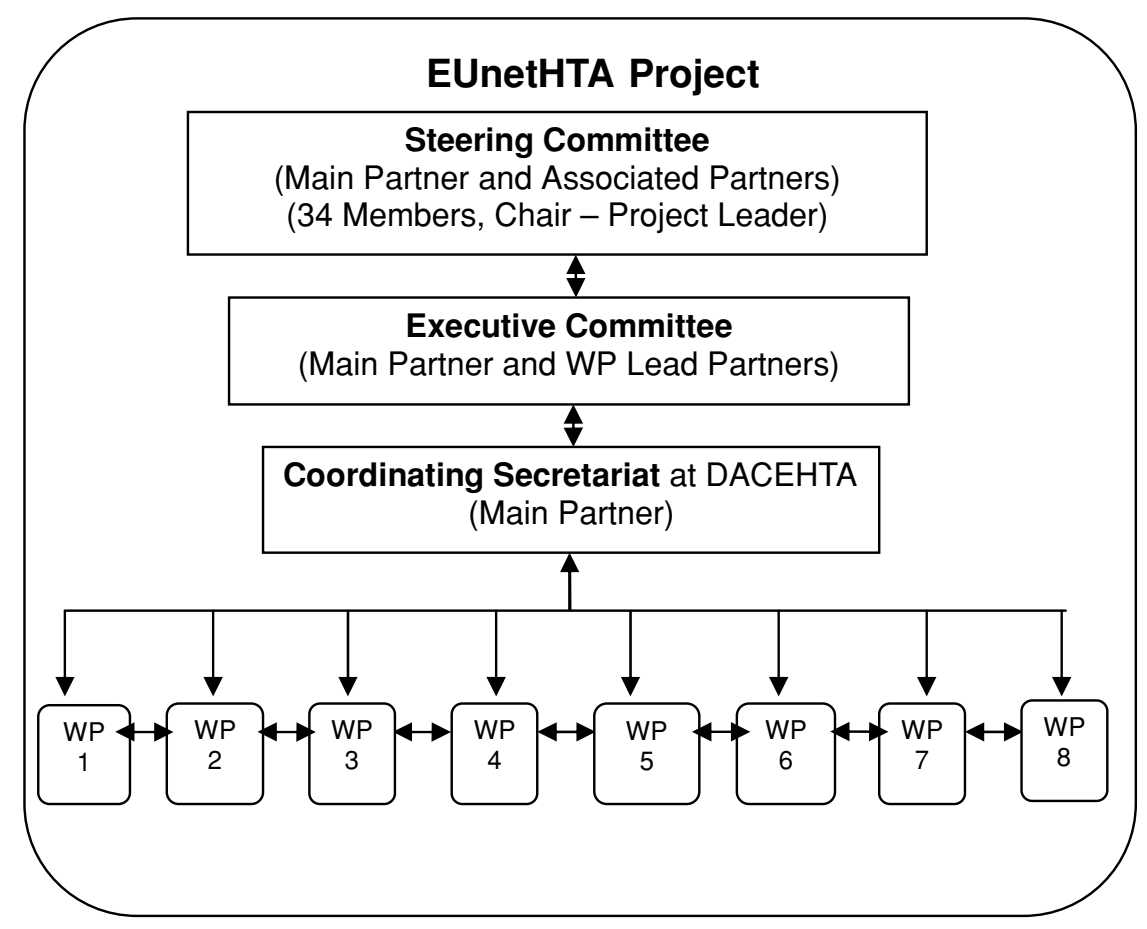

Figure 1. Governance structure.

supported by the Secretariat, which led and managed the Project day-to-day (Figure 1).

\section{Information, Communication, and Clearinghouse}

Early in the project, EUnetHTA was given a distinct visual identity by way of name, logotype, symbols, fonts, imagery, and colors. EUnetHTA's Communication Strategy was finalized in the first year (1). The EUnetHTA Information Platform included a public Web site (www.eunethta.net) with a members-only area and eight extranets, one for each WP. The Web site included several communication support tools. The intermediary results from the WPs were circulated by means of e-mail and on the members-only site. The final results were published on the public Web site. The international HTA community was informed about the European developments during the project (8).

In spring 2008, the Lead Partner organizations reviewed the functionality of the WP2 description of a prototype of a single point of access (Clearinghouse) to all HTA-relevant information. As a result of this review, an incremental approach was chosen. By end of the Project, the HTA Information System included the EUnetHTA Web site as a user-friendly platform and interface with databases, checklists, and other useful tools for the Partners and as a platform for integrating the information and tools developed in the WPs (1).

\section{Stakeholder Involvement}

Work Package 6 (WP6) identified five stakeholder groups at the European level as potentially sharing an interest in
EUnetHTA and its products: (i) Policy makers at national and regional levels, (ii) Policy makers at the institutional level, (iii) Patient organizations, (iv) Healthcare professionals, and (v) Industry.

WP6 developed a Stakeholder Open Forum on the EUnetHTA Web site (http://www.eunethta.net/Stakeholder_ Forum/Home/) with a "Frequently Asked Questions" section and links to important stakeholder policy statements on HTA (http://www.eunethta.eu/Stakeholder_Forum/ Activities_for_Stakeholders/). A draft stakeholder policy for the EUnetHTA Collaboration was developed and discussed with stakeholders in a face-to-face meeting in 2008 (11).

\section{Internal Evaluation}

The main outcome of evaluation was that the Project succeeded in developing tools aimed at providing a common methodology with the intent to establish a suggested standard for conducting and reporting HTA and facilitating increased collaboration between agencies. The participants expressed their belief in a network while maintaining local/national autonomy. The WP Lead Partners expressed a strong belief that the solid base provided by the Project would serve as a future network, but were aware of the need for funding and government support (23).

\section{Additional Spin-offs}

During the Project, some of the Partners took the opportunity of using the network to collaborate in producing 
reports on vaccination against HPV-related cervical cancer and treatment of age-related macular degeneration (www. eunethta.net).

\section{Proposal for Permanent EUnetHTA Collaboration}

The EUnetHTA Project's proposal for continuation after 2008 was published in June 2008 (9). The document focused on HTA collaboration in Europe and described a strategic plan including mission, aims, added value, participants, functions, levels of collaboration, organization, and possible funding. It also described a process to be initiated by a group of Founding Partners in summer 2008 to bring about the continuation of EUnetHTA in a sustainable form.

\section{Establishing Permanent EUnetHTA Collaboration}

During the last half year of the Project, twenty-five Founding Partners teamed together to secure the EUnetHTA Collaboration. Hence, by the end of the third year the continuation of a secretariat and several functions were secured by direct contributions and in-kind contributions from institutions in thirteen EU Member States, Norway, and Switzerland for the year 2009 (10).

\section{DISCUSSION}

It proved to be an essential success element to have a wellfunctioning and clear management and governance structure and an information and communication platform to support the scientific work of a vast number of participating organizations that worked together across borders to achieve the objective of developing practical tools for transnational collaboration. These tools are described in Kristensen et al. (22). Supported by the secretariat the Executive Committee was able to identify and solve problems of coordination and collaboration and reach shared decisions on internal issues and external relations. As reflected in the evaluation (23), the degree of commitment varied considerably across the many partners, and it proved difficult to turn all partners into active participants.

By being an active agent in European health policy the Executive Committee facilitated the political support for a sustainable network, including developing stakeholder relations. The following developments reflect this active approach.

\section{Recognition of HTA and EUnetHTA in Health Policy Developments in Europe}

The Tallinn Charter adopted at the Ministerial Conference in the WHO European Region, June 2008, stated that HTA should be used to support more informed decision making (28).
In July 2008, the EU Commission issued a proposal for a directive on the application of patient rights in cross-border healthcare. An article in the proposal concerns cooperation on HTA to facilitate development and functioning of a network connecting the national authorities or bodies responsible for HTA (7). A communication from the Commission mentioned EUnetHTA, and stated, "A clear framework for taking forward these activities can be established under the directive on the basis of the results of this" (5). The final wording of this directive has not been reached by the EU legislative system.

In addition, discussion and conclusions on relative effectiveness in the Pharmaceutical Forum lead in the direction of HTA methodology. The Steering Committee of the Pharmaceutical Forum acknowledged that EUnetHTA could be a relevant candidate for taking forward the scientific recommendations (16).

\section{Joint Action Between EU Member States and the Commission}

As a result of a decision in early 2009 between the EU and Member-State-appointed HTA bodies and representatives, a 3-year Joint Action (2010-12) under the EU Health Program (2008-13) will be the basis for continuation of European networking in HTA and further work on relative effectiveness assessment of pharmaceuticals as a follow-up to the Pharmaceutical Forum $(6 ; 16)$. EUnetHTA was asked to bring the Joint Action forward, thus implementing the aim of sustainability of a European network for HTA at the request of governments and the European Commission. EUnetHTA's Joint Action proposal was favorably evaluated by the Commission. Partner institutions in Member States and the EU will provide funding, and a contract with the European Commission will be negotiated during the autumn of 2009. After 2012, sustainability is assumed to be ensured through an EU Directive mechanism. However, the process of adopting and implementing a Directive, which would include an article on a network of European HTA institutions, and its implementation at the Member States level, is highly political and will most likely take several years.

\section{CONCLUSION}

The practical nature of the EUnetHTA Project, and a transparent governance and management structure, helped to achieve tangible results that should create added value for HTA in Europe. It enabled close collaboration among many organizations and individuals across national borders, cultures, and the systems facilitating change. A policy for stakeholder involvement and a proactive responsiveness to policy needs in Europe have formed a solid foundation for innovative transnational cooperation on HTA. This has positioned EUnetHTA at the center of committed collaboration on HTA between EU Member States and the Commission, as implemented in the Joint Action to ensure the continuation and development of HTA in the EU. 
The role of HTA is to inform policy and decision making in context. Due to the political nature of cross-border healthcare issues, EUnetHTA Collaboration should be responsive to political developments in Europe. This should be balanced with maintaining a high level of ambition to promote the use HTA through joint development of independent, evidencebased information, and well-tested tools for best practice in national and regional HTAs based on a strong network of HTA institutions - to the ultimate benefit of citizens in Europe.

\section{SUPPLEMENTARY MATERIALS}

Supplementary Table 1

Supplementary Table 2

Supplementary Table 3

Supplementary List 1

www.journals.cambridge.org/thc2009004

\section{CONTACT INFORMATION}

Finn Børlum Kristensen, MD, PhD (fbk@sst.dk), Director, Danish Centre for Health Technology Assessment, National Board of Health, Islands Brygge 67, DK-2300 Copenhagen S, Denmark; Adjunct Professor, Faculty of Health Sciences, University of Southern Denmark, Winsløwparken 19, 3, Odense C, DK 5000, Denmark

Marjukka Mäkelä, MD, PhD, MSc (marjukka.makela@ thl.fi), Director, Finnish Office for Health Technology Assessment, National Institute for Health and Welfare, P.O. Box 30, 00271 Helsinki, Finland; Professor, Department of General Practice, University of Copenhagen, P.O. Box 2099, 1014 Copenhagen K, Denmark

Susanna Allgurin Neikter (allgurin@sbu.se), Marketing Director, Swedish Council on Technology Assessment in Health Care (SBU), Olof Palmes Gata 17, P.O. Box 3657, SE-103 59, Stockholm, Sweden

Nina Rehnqvist, MD, PhD (rehnqvist@sbu.se), Chairperson, Swedish Council on Technology Assessment in Health Care, P.O. Box 3657, SE-103 59 Stockholm, Sweden; Adjunct Professor, Department of Medicine, Karolinska Institute, SE-171 76 Stockholm, Sweden

Lise Lund Håheim, DDS, PhD (llh@ nokc.no), Senior Researcher, Department for Quality Measurement and Patient Safety, Norwegian Knowledge Centre for the Health Services, Pilestredet Park 7, Oslo, N-0130, Norway

Berit Mørland, DDS, Dr. phil. (beritt.morland@nokc.no), Deputy Director General, Norwegian Knowledge Centre for the Health Services, P.O. Box 7004, St. Olavs plass, N-0130 Oslo, Norway

Ruairidh Milne, MB, BS, FFPH (rm2@soton.ac.uk), Senior Lecturer in Public Health, National Coordinating Centre for Health Technology Assessment, University of Southampton, Alpha House, University of Southampton Science Park, Southampton SO16 7NS, UK
Camilla Palmhøj Nielsen, MA, PhD student (cpn@ sst.dk), Special Advisor, Danish Centre for Health Technology Assessment, National Board of Health, Islands Brygge 67, DK-2300 Copenhagen S, Denmark; PhD Student, Department of Political Science, University of Copenhagen, Østre Farimagsgade 5, DK-1353 Copenhagen K, Denmark

Reinhard Busse, Professor Dr. med., MPH, FFPH (rbusse@ tu-berlin.de), Professor and Director, Department of Health Care Management, Technische Universität Berlin, Str. des 17, Juni 135, 10623 Berlin, Germany

Sun Hae Lee-Robin, MD, MPH (sh.leerobin@ has-sante.fr), Head of Department, Medical and Surgical Procedures Assessment, French National Authority for Health, 2 avenue du Stade de France, Saint-Denis La Plaine CEDEX, F-93218, France

Claudia Wild, Dr. phil. (claudia.wild@hta.lbg.ac.at), Director, Ludwig Boltzmann Institute of Health Technology Assessment, Garnisongasse 7/20, 1090 Vienna, Austria

Mireia Espallargues, MD, $\mathrm{PhD}$ (mespallargues@ aatrm.catsalut.net), Assistant Director for Health Care Quality Assessment, Health Care Quality, Catalan Agency for Health Technology Assessment and Research, Carrer de Roc Boronet, 81-95 (2a planta), E-08005, Barcelona, Spain Julia Chamova, MBA (juch@sst.dk), Project Coordinator, Monitoring and Health Technology Assessment, National Board of Health, Islands Brygge 67, DK-2300 Copenhagen, Denmark

\section{REFERENCES}

1. Allgurin Neikter S, Rehnqvist N, Rosén M, Dahlgren H. Toward a new information infrastructure in health technology assessment: Communication, design, process, and results. Int $J$ Technol Assess Health Care. 2009;25(Suppl 2):92-98.

2. Banta D, Kristensen FB, Jonsson E. A history of health technology assessment at the European level. Submitted. Int J Technol Assess Health Care. 2009;25(Suppl 1):68-73.

3. Banta D. Introduction to the EUR-ASSESS report. Int J Technol Assess Health Care. 1997;13:133-143.

4. Banta HD, Oortwijn W. Conclusion: Health technology assessment and health care in the European Union. Int J Technol Assess Health Care. 2000;16:626-635.

5. Commission of the European Communities. Communication from the Commission. A Community framework on the application of patients' rights in cross-border healthcare, July 2, 2008. Available at: http://ec.europa.eu/health/ph_overview/ co_operation/healthcare/docs/COM2008415_en.pdf (accessed February 18, 2009).

6. Commission of the European Communities. Executive agency for health and consumers. 2009 Call for Proposals for Joint Actions. Available at: http://ec.europa.eu/eahc/documents/health/ calls/2009_CALL_JOINT_ACTIONS.pdf (accessed March 5, 2009).

7. Commission of the European Communities. Proposal for a directive of the European parliament and the Council on the application of patients' rights in cross-border healthcare, July 2, 2008. Available at: http://ec.europa.eu/health/ph_overview/ 
co_operation/healthcare/docs/COM_en.pdf (accessed February 18, 2009).

8. EUnetHTA. First_results_delivered_by_EUnetHTA. Report_ from_the_EUnetHTA_workshop_June_17, 2007,_Barcelona_ Spain. Available at: http://www.eunethta.eu/Public/News_ archive/First_results_delivered_by_EUnetHTA_report_from_ the_EUnetHTA_workshop_June_17_Barcelona_Spain/.

9. EUnetHTA. Proposal for the EUnetHTA Collaboration, June 16, 2008. Available at: http://www.eunethta.net/Public/ News_archive/EUnetHTA_Collaboration_Proposal_-_way_ forward_for_HTA_in_Europe/.

10. EUnetHTA. Welcome to EUnetHTA. Available at: http://www. eunethta.net/Public/Contact/Founding_Partners (accessed October 2009).

11. EUnetHTA. Work Package 6. Draft stakeholder policy for the EUnetHTA Collaboration 2009. Available at: http://www. eunethta.net/upload/Stokeholder_Forum/June\%2013\%20Stoc kholder\%20meeting/Annex\%207.\%20Draft\%20Stokeholder\% 20Policy.pdf.

12. European Commission. High Level Group on innovation and provision of medicines in the European Union. Recommendations for action. Available at: http://ec. europa.eu/health/ph_overview/Documents/key08_en.pdf (accessed February 18, 2009).

13. European Health Forum Gastein 2007. Health sans frontiers. Available at: http://www.ehfg.org/fileadmin/ehfg/ Website/Archiv/2006/Dokumente/EHFG_2006_web_rev_2. pdf (accessed February 18, 2009).

14. European Union. Health and Consumer Protection DirectorateGeneral. High Level Group on Health Services and Medical Care. High level process of reflection on patient mobility and healthcare developments in the European Union. Outcome of the reflection process, 9 December 2003. Available at: http://ec.europa.eu/health/ph_overview/Documents/key01_ mobility_en.pdf (accessed February 18, 2009).

15. European Union. Health and Consumer Protection DirectorateGeneral. High Level Group on Health Services and Medical Care. Report from the High Level Group to the Employment, Social Affairs, Health and Consumer Protection Council on 67 December 2004. Available at: http://ec.europa.eu/health/ph_ overview/co_operation/healthcare/docs/highlevel_2004_026_ en.pdf (accessed February 18, 2009).

16. High Level Pharmaceutical Forum. Final Report, October 2, 2008. Available at: http://ec.europa.eu/pharmaforum/ docs/ev_20081002_frep_en.pdf (accessed February 18, 2009).

17. International Network of Agencies for Health Technology, Stockholm, Sweden. Available at: http://www.inahta.org/ upload/HTA_resources/ (accessed February 18, 2009).

18. International Network of Agencies for Health Technology,
Stockholm, Sweden. HTA Database. Available at: http://www. inahta.org/HTA/Database (accessed February 18, 2009).

19. Network of Agencies for Health Technology, Stockholm, Sweden. Publications. Available at: http://www.inahta. org/Publications/Post.aspx (accessed December 15, 2008).

20. Jonsson E, Banta D, Henshall C, Sampietro-Colom L. Executive summary of the ECHTA/ECAHI Project. Int J Technol Asses Health Care. 2002;18:213-217.

21. Kristensen FB. EUnetHTA and health policy-making in Europe. Eurohealth. 2006;12:36-38. Available at: http://www.lse.ac. uk/collections/LSEHealth/pdf/eurohealth/vol12no1.pdf (accessed February 18, 2009).

22. Kristensen FB, Lampe K, Chase DL, et al. Practical tools and methods for health technology assessment in Europe: Structures, methodologies, and tools developed by the European network for Health Technology Assessment, EUnetHTA. Int J Technol Assess Health Care. 2009;25(Suppl 2):1-8.

23. Lund Håheim L, Imaz I, Laeubli M, et al. Internal evaluation of the European network for Health Technology Assessment project. Int J Technol Assess Health Care. 2009;25(Suppl 2):99106.

24. Swedish Council on Technology Assessment in Health Care. Obstructive sleep apnoea syndrome-Report of a joint Nordic project. Stockholm: SBU; 2007.

25. Palmhøj Nielsen C, Wadmann Lauritsen S, Kristensen FB, et al. Involving stakeholders and developing a policy for stakeholder involvement in the European network for Health Technology Assessment, EUnetHTA. Int J Technol Assess Health Care. 2009;25(Suppl 2):84-91.

26. Sorensen C, Drummond M, Kanavos P. Ensuring value for money in health care. The role of health technology assessment in the European Union. Copenhagen: World Health Organisation; 2008. Available at: http://www.euro.who. int/document/E91271.pdf (accessed February 18, 2009).

27. Velasco-Garrido M, Zentner A, Busse R. Health systems, health policy and health technology assessment. In: Velasco-Garrido M, Børlum Kristensen F, Palmhøj Nielsen C, Busse R, eds. Health technology assessment and health policy-making in Europe: Current status, challenges and potential. Copenhagen: WHO Regional Office for Europe; 2008:53-78.

28. WHO European Ministerial Conference on Health Systems. The Tallinn Charter: Health systems for health and wealth, Tallinn, Estonia, 25-27 June 2008. Available at: http://www.euro.who.int/document/E91438.pdf (accessed February 18, 2009).

29. WHO European Ministerial Conference on Health Systems. WHO European Ministerial Conference on Health Systems, Tallinn, Estonia,25-27 June 2008. Available at: http://www. euro.who.int/healthsystems2008 (accessed February 18, 2009). 